Review

\title{
Review of OPFRs in animals and humans: Absorption, bioaccumulation, metabolism, and internal exposure research
}

\author{
Rui Hou ${ }^{\text {a, b }}$, Yiping Xu ${ }^{\text {a, * }}$, Zijian Wang ${ }^{b}$ \\ ${ }^{a}$ Key Laboratory of Drinking Water Science and Technology, Research Center for Eco-Environmental Sciences, Chinese Academy of Sciences, Beijing 100085, \\ PR China \\ b State Key Laboratory of Environmental Aquatic Chemistry, Research Center for Eco-Environmental Sciences, Chinese Academy of Sciences, Beijing 100085, \\ PR China
}

\section{H I G H L I G H T S}

- The absorption, bioaccumulation, metabolism and internal exposure of OPFRs are reviewed.

- Inhalation, ingestion and dermal contact are the main OPFRs absorptionpathways for humans.

- General in vivo and in vitro metabolic pathways of three different types of OPFRs are proposed.

- DAPs and MAPs are considered as putative biomarkers for the assessment of internal exposure of OPFRs in humans.

\section{A R T I C L E I N F O}

\section{Article history:}

Received 7 January 2016

Received in revised form

1 March 2016

Accepted 2 March 2016

Available online 21 March 2016

Handling Editor: J. de Boer

\section{Keywords:}

Organophosphorus flame retardants

(OPFRs)

Absorption

Bioaccumulation

Metabolism

Internal exposure

\begin{abstract}
A B S T R A C T
Due to their widespread use, organophosphate flame retardants (OPFRs) are commonly detected in various environmental matrices and have been identified as emerging contaminants. Considering the adverse effects of OPFRs, many researchers have paid their attention on the absorption, bioaccumulation, metabolism and internal exposure processes of OPFRs in animals and humans. In this article, we first review the diverse absorption routes of OPFRs by animals and humans (e.g., inhalation, ingestion, dermal absorption and gill absorption). Bioaccumulation and biomagnification potentials of OPFRs in different types of organisms and food webs are also summarized, based on quite limited available data and results. For metabolism, we review the Phase-I and Phase-II metabolic processes for each type of OPFRs (chlorinated OPFRs, alkyl-OPFRs and aryl-OPFRs) in the animals and humans, as well as toxicokinetic information and putative exposure biomarkers on OPFRs. Finally, we highlight gaps in our knowledge and critical directions for future internal exposure studies of OPFRs in animals and humans.
\end{abstract}

(1) 2016 Elsevier Ltd. All rights reserved.

\section{Contents}

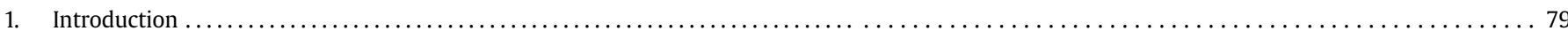

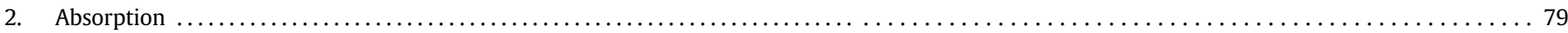

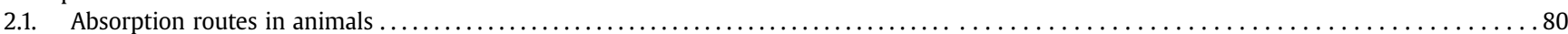

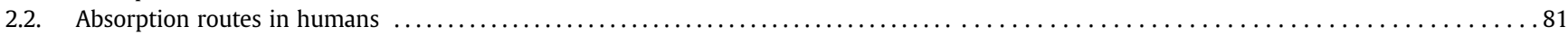

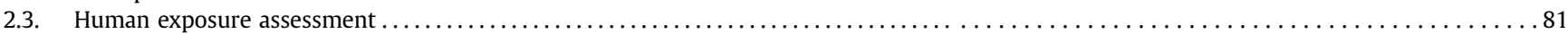

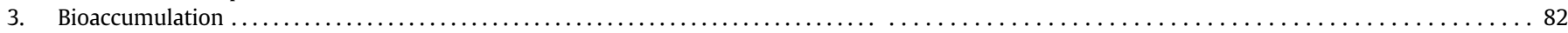

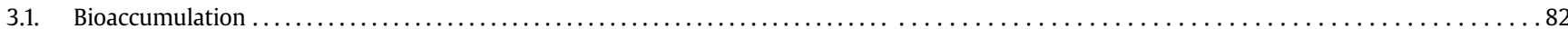

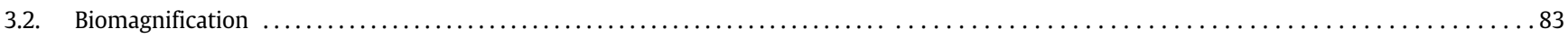

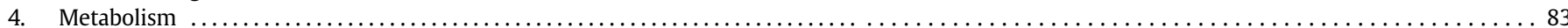

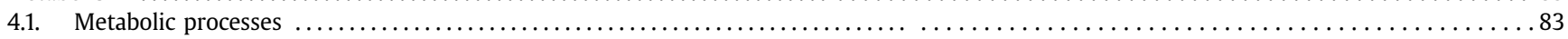

\footnotetext{
* Corresponding author.

E-mail address: ypxu@rcees.ac.cn (Y. Xu).
} 


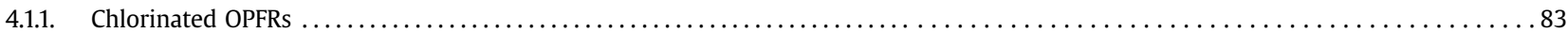

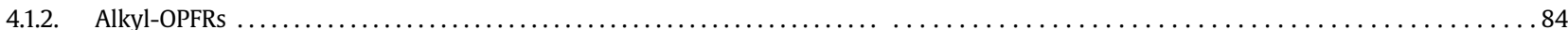

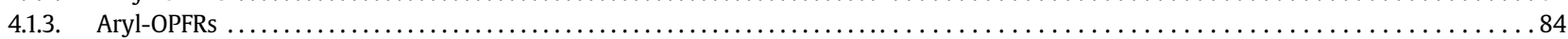

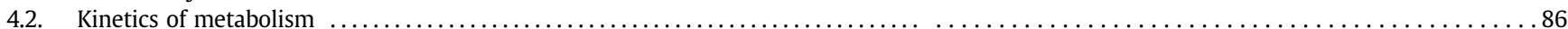

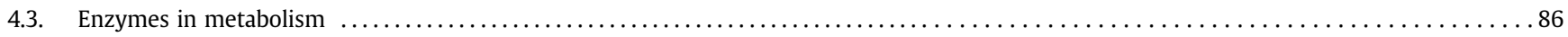

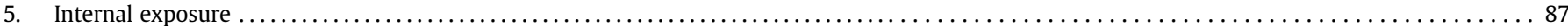

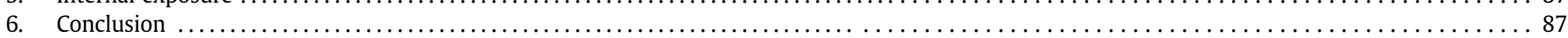

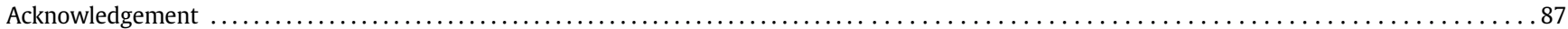

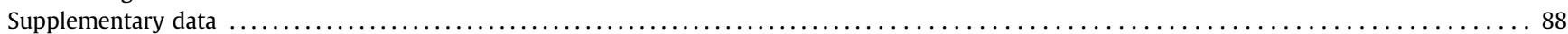

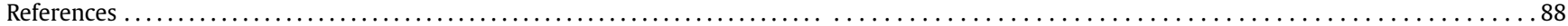

\section{Introduction}

Organophosphorus flame retardants (OPFRs), which extensively used in furniture, textiles, mattresses, electronics and other processing chemicals, constitute one of the most frequently used flame retardants (EPA, 2005). OPFRs are being increasingly consumed since the restriction published on the use of penta- and octapolybrominated diphenyl ethers (PBDEs) (Marklund et al., 2005b; Van der Veen and de Boer, 2012). According to statistical data, the consumption of OPFRs in Europe had reached to 85,000 tonnes in 2005 (EFRA, 2007). China produced more than 70,000 tons of OPFRs in 2007 (Wang et al., 2010). The global consumption of OPFRs was 500,000 tonnes in 2011 and was expected to 680,000 tonnes in 2015 (Van der Veen and de Boer, 2012; Wang et al., 2015a).

OPFRs basically exist in end-products by physical addition, which is responsible for their leakage from products during service time through volatilization, abrasion and leaching (Sundkvist et al., 2010). After emission, there are several ways in which OPFRs can reach remote areas, such as deposition, washout, infiltration, etc. (Andresen et al., 2004; Bacaloni et al., 2008; Schreder and La Guardia, 2014; Takimoto et al., 1999). Atmospheric washout by precipitation and industrial discharge from factories and wastewater treatment plants (WWTPs) have been identified as the most significant entry modes of OPFRs into aquatic and terrestrial systems (Cristale et al., 2013; Meyer and Bester, 2004; Wei et al., 2015). As a result, OPFRs are globally distributed and ubiquitously present in various environmental mediums, such as dust, indoor air, atmosphere, surface water, sediment and soil (Cequier et al., 2014b; Chung and Ding, 2009; Gao et al., 2014; Kim et al., 2011; Staaf and Ostman, 2005). A number of studies have found that indoor environments have significantly higher levels of OPFRs than brominated flame retardants (BFRs) (Ali et al., 2012; Brommer et al., 2012; He et al., 2015). Over the past decade, almost all of the OPFRs produced have been detected in marine and fresh water animal, avian, insect and human samples (SI Table S1).

OPFRs are synthetic phosphoric acid derivatives, whose structures vary depending on different ester linkages and can be roughly divided into three types: chlorinated OPFRs, alkyl-OPFRs and arylOPFRs (Table 1, where the abbreviations of the OPFRs in this review are provided). OPFRs have a wide range of physiological properties in the environment. For example, their solubility, log $\mathrm{K}_{\mathrm{OW}}$ values, persistence, vapor pressure, bioconcentration factors (BCFs) are quite different (Table 1). These properties are important factors in assessing the behavior of OPFRs in the environment and for assessing their influence on organisms (Van der Veen and de Boer, 2012). Volatile OPFRs with higher vapor pressures, such as TBP, TEP and TCEP, tend to be more likely to emit into air and settled onto dust than heavier OPFRs (Wei et al., 2015). Aryl and alkyl-OPFRs with higher molecular mass are more hydrophobic, have similar BCFs and have an affinity for sediment and soil (Van der Veen and de Boer, 2012; Wei et al., 2015). Chlorinated OPFRs have been shown to be more water soluble and are considered to be persistent threats to aquatic animals (Reemtsma et al., 2008; Van der Veen and de Boer, 2012).

Considering the occurrence of OPFRs in organisms and in organisms' surroundings, increasing attention has been devoted to their adverse effects to organisms. Toxicological studies have shown that OPFRs have the potential to cause adverse reproductive, endocrine and systemic effects in animals as a result of long term exposure to animals (Dishaw et al., 2011; Liu et al., 2012; Porter et al., 2014; Van der Veen and de Boer, 2012). Aryl-OPFRs have been shown to contribute to heart toxicity by disturbing the expression of transcriptional regulators in zebrafish (Du et al., 2015). Chlorinated OPFRs, such as TCEP, TCIPP and TDCIPP, have been proven to be neurotoxic and carcinogenic (Ni et al., 2007; WHO, 1998, 2000). TDCIPP can easily enter the blood stream and induce tumors in the liver, kidney and testis (OEHHA, 2011). TDCIPP levels in house dust were found to be correlated with reduced concentrations of thyroid hormones (THs) levels and increased prolactin levels in males (Meeker and Stapleton, 2010). TDCIPP and TCEP are prohibited in Washington State, USA, according to the "Toxic Free Kids Act" (Washington Toxics Coalition, 2011). EU Directive 2014/81/EU also introduced specific limits $\left(5 \mathrm{mg} \mathrm{kg}{ }^{-1}\right.$ ) for TCEP, TCIPP and TDCIPP in certain toys (European Union Commision Directive, 2014).

Studies of the bioaccumulation, metabolism and toxicokinetics of OPFRs date back to the 1970s (Gold et al., 1978; MacFarland and Punte, 1966; Muir et al., 1980; St. John et al., 1976). Fewer studies had been conducted until concerns were raised regarding the reemergence of OPFRs due to their increasing usage and high environmental concentrations (Carlsson et al., 2000). To date, the behaviors of OPFRs in animals and humans have become hotbutton issues. However, these long-term studies still have not been fully summarized. Studies of the absorption, bioaccumulation and metabolic processes will facilitate comprehension of the fates and the mechanisms of toxicity of OPFRs. Thus, a review of the available studies in a systematic framework is urgently needed to better understand the behaviors and fates of OPFRs in organisms. In this article, we organized recent studies on the absorption, bioaccumulation, biomagnification and the metabolic processes of OPFRs in animals and humans (Fig. 1), rather than simply listing the occurrences of OPFRs in biota, which has often been conducted in previous reviews (Alves et al., 2014; Reemtsma et al., 2008; Van der Veen and de Boer, 2012; Wei et al., 2015). In addition, we also propose a perspective on research into the internal exposure of OPFRs to animals and humans.

\section{Absorption}

The migration of OPFRs in the environment leads to their exposure to organisms (Abdallah and Covaci, 2014; Alves et al., 2014). There are diverse pathways for organisms to uptake or 
Table 1

The names, abbreviations, structures and properties of the studied OPFRs.

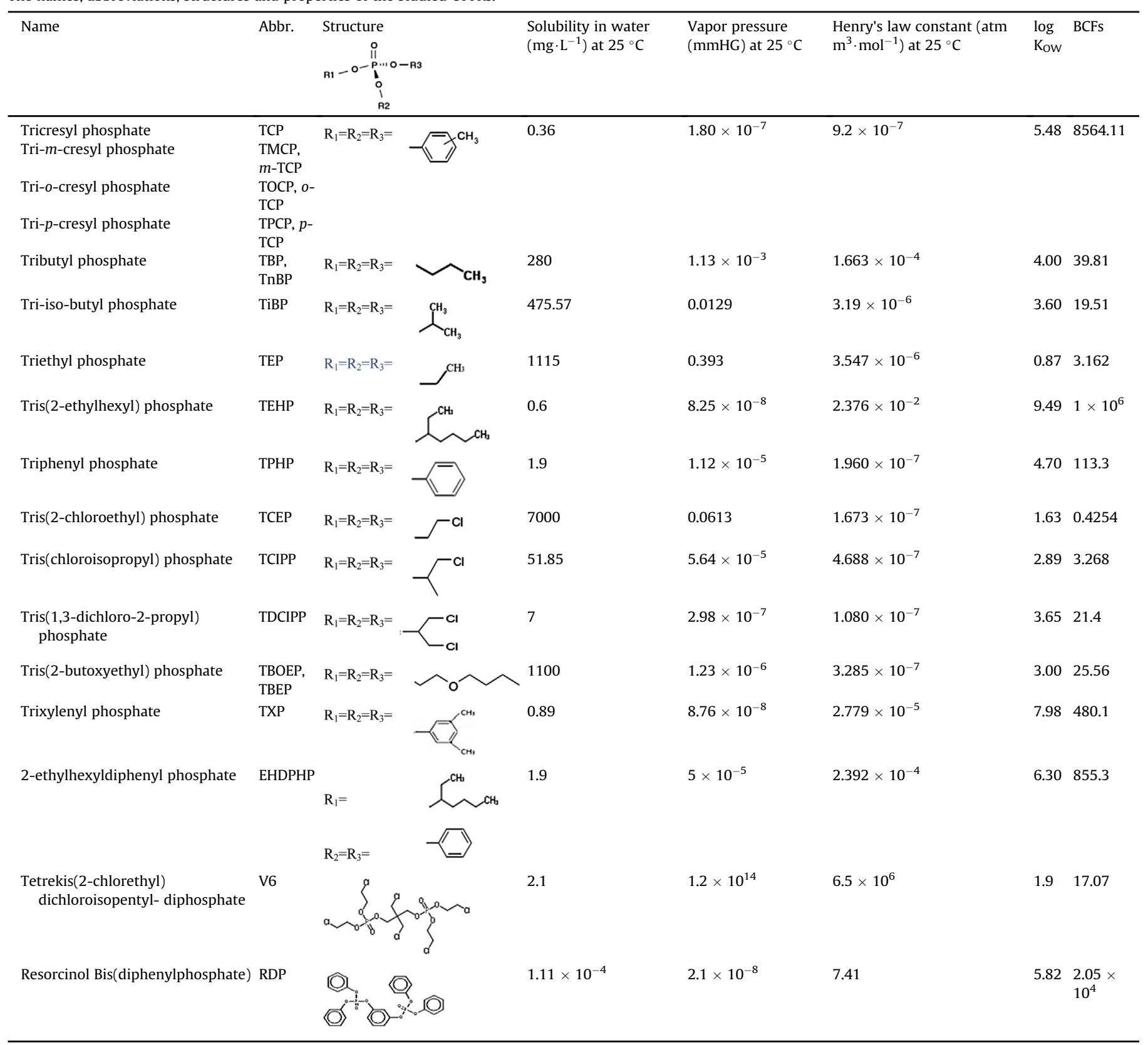

The data are compiled from databases (Chemspider, 2015) and Van der Veen and de Boer (2012).

absorb OPFRs through ingestion, gill absorption, skin absorption and inhalation. Several reports over the past decade have provided insight into these routes of absorption in animals and humans.

\subsection{Absorption routes in animals}

Gill absorption may be one of the most common ways in which aquatic animals take up OPFRs dissolved in ambient water. In an investigation of the distribution of OPFRs in fish, researchers found that OPFRs were primarily absorbed from water through the gills and epithelial tissue rather than through food web biomagnification (Malarvannan et al., 2015; Sundkvist et al., 2010). Kim et al. (2011) also indicated that the gill contributed greatly uptake of OPFRs from water for fish. However, very few studies have thoroughly examined the uptake of OPFRs in aquatic organisms through gill membranes.

Ingestion is assumed to be another critical pathway for OPFRs to enter the bodies of animals (Sundkvist et al., 2010). Because OPFRs are present in biota, it is possible for predators at the top of the food chain to consume more OPFRs (Eulaers et al., 2014). Studies have shown that TBOEP, TCIPP and TCEP can spread in the benthic and pelagic food web and be detected in predators (e.g., sculpin, plaice, goby, sole and tern) (Brandsma et al., 2015). For terrestrial birds and mammals, OPFRs can also be absorbed by ingestion of food and water. However, few studies have focused on this route of absorption, except for a study in White-tailed Eagles, in which diet was identified to be the primary means of OPFR absorption (Eulaers et al., 2014).

However, there is insufficient knowledge regarding the different routes by which variant OPFRs can enter organisms under different 


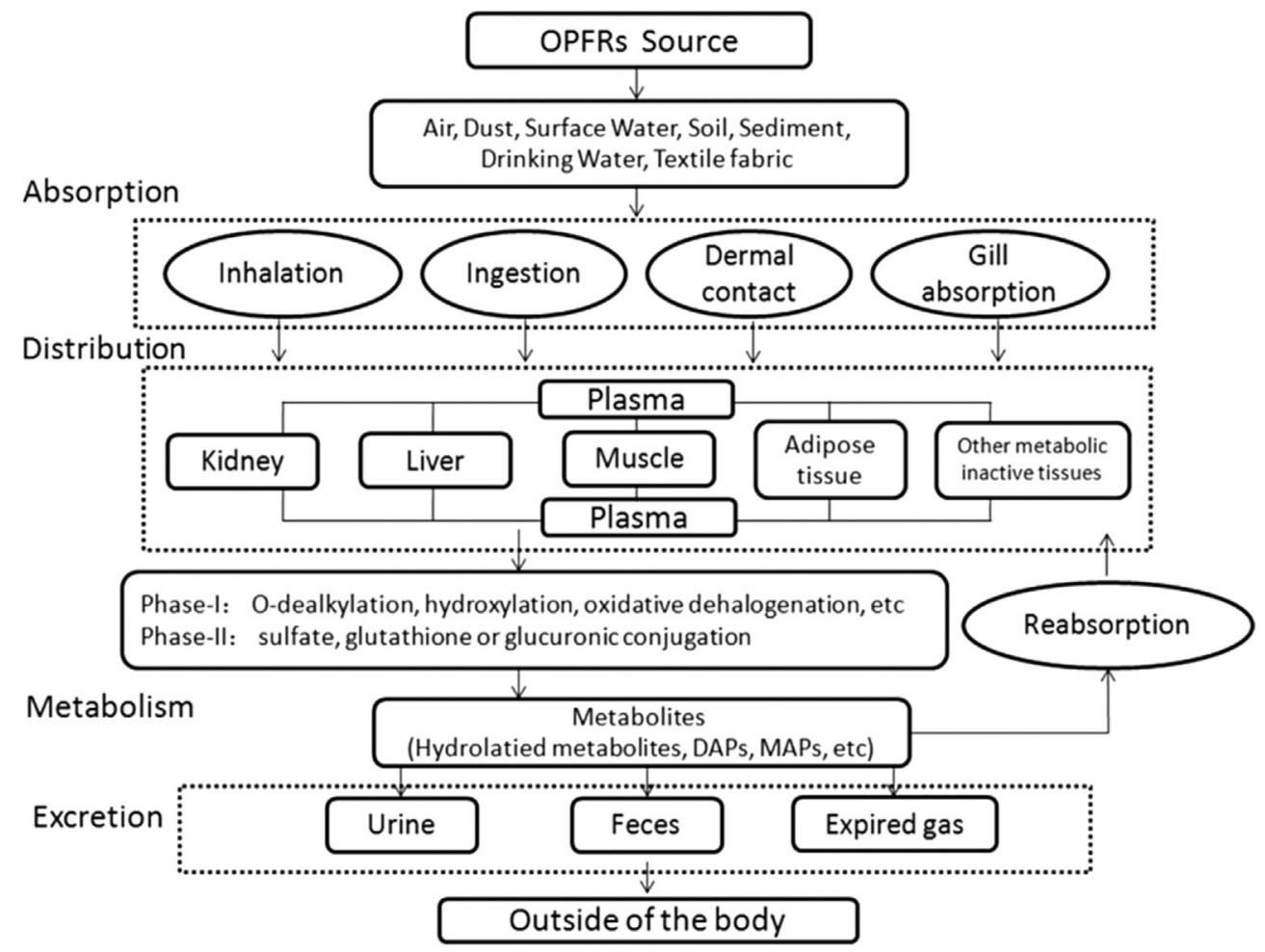

Fig. 1. A schematic representation of the fate of OPFRs in the body of animals and humans.

environmental conditions. Additionally, exposure assessments of the biological effects of OPFRs in wildlife have not been studied. Therefore, further research assessing the exposure thresholds of OPFRs for organisms is recommended.

\subsection{Absorption routes in humans}

Several studies have found that inhalation of indoor air and dust is one of the most important OPFR absorption pathways for people living in indoor environments because building materials are considered to be a significant source of OPFRs (Marklund et al., 2005b; Tajima et al., 2014; Yang et al., 2014). TPHP, TBP, TBOEP, TCEP and TCIPP are the most frequently identified and most abundant compounds among the detected OPFRs in indoor air and dust (Abdallah and Covaci, 2014; Cequier et al., 2014b; Tajima et al., 2014). Moreover, OPFRs exposure through inhalation may be more threatening for people that spend time in offices than PBDEs exposure as more OPFRs are used as alternatives for PBDEs in indoor environments (Tajima et al., 2014; Van der Veen and de Boer, 2012; Wei et al., 2015). OPFRs have also been detected in atmosphere, but their contributions to inhalation are often neglected due to their relatively lower levels in these environments (13-20,300 pg $\mathrm{m}^{3}$ ) (Wei et al., 2015).

Moreover, dietary exposure of OPFRs via food and drinking water is a major concern for the general population (Li et al., 2014; WHO, 1990, 1991, 1997, 1998, 2000). Fishes were investigated their contribution to OPFRs exposure to human in lakes and coastal areas. In many environmental surveys of fish worldwide, OPFRs concentrations have been reported to be as high as $15,000 \mathrm{ng} \mathrm{g}^{-1}$ (SI Table S1). Ingestion of OPFRs through drinking water cannot be neglected, as the occurrence of OPFRs in drinking water has been established in published literature (Benotti et al., 2009; Li et al., 2014; Stackelberg et al., 2007). Moreover, foodstuffs consumed by humans can be contaminated with OPFRs due to the use of OPFR- containing packaging plastics (Campone et al., 2010).

Skin also contributes to the total uptake of OPFRs. Touching contaminated water or direct contact with OPFR-containing products may result in the entry of OPFRs into the body through dermal uptake (St John et al., 1976). It has been verified that TDCIPP can be absorbed by human skin (Gold et al., 1978; Nomeir et al., 1981). Accidental exposure of TEHP, TBOEP, TBP and TCP by the dermal route during the manufacturing and use of some products has attracted much attention (WHO, 1990, 1991, 2000). In addition, Hoffman et al. (2015) found the strong relationship between the levels of TDCIPP and TPHP on hand wipes and the levels of their metabolites in urine and suggested that hand-to-mouth contact or dermal absorption may be important absorption pathways of OPFRs.

For the contribution of different absorption pathways, Sundkvist et al. (2010) suggested that humans exposure OPFRs through eating fish was less important than indoor dust inhalation in lakes and coastal areas in Sweden. Cequier et al. (2014a) found that the relative contribution of dermal contact with TDCIPP to total OPFR uptake (i.e. $45 \%$ to the intake for children and $58 \%$ for women) was as important as inhalation for children and mothers (i.e. $54 \%$ and $41 \%$, respectively) in Oslo, Norway. Cequier et al. (2015) subsequently concluded the household inhalation was a more important absorption pathway of OPFRs than through the diet for motherchild pairs in Norway. But more biomonitoring studies are needed to further discuss the contribution of various absorption pathways of OPFRs for human.

\subsection{Human exposure assessment}

Numerous recent studies have focused on estimating the impact of OPFRs on human health, but information is only available about exposure assessments through inhalation and ingestion.

Most assessments of human exposure to OPFRs via inhalation worldwide are based on the concentrations of OPFRs that are 
Table 2

Statistical summary of human exposure assessment to OPFRs via inhalation.

\begin{tabular}{|c|c|c|c|c|c|c|c|c|c|c|c|c|}
\hline \multirow[t]{2}{*}{ Country } & \multirow[t]{2}{*}{ Category } & \multicolumn{10}{|c|}{ Human exposure to OPFRs $\left(\mathrm{ng} \cdot(\mathrm{kg} \mathrm{d})^{-1}\right)$} & \multirow[t]{2}{*}{ References } \\
\hline & & TCIPP & TCEP & TDCIPP & TBOEP & TBP & EHDPP & TEHP & ТPHP & TCP & ¿OPFRs & \\
\hline \multirow[t]{2}{*}{ Sweden } & Adult & - & - & - & - & - & - & - & - & - & 5800 & Marklund et al. (2005a) \\
\hline & Children & - & - & - & - & - & - & - & - & - & 57,000 & \\
\hline \multirow[t]{2}{*}{ Belgium } & Adult & 0.5 & 0.1 & - & 0.7 & 1.1 & - & - & 0.2 & 0.1 & 2.7 & Van den Eede et al. (2011) \\
\hline & Toddler & 5.6 & 1.0 & - & 8.2 & 12.7 & - & - & 2.0 & 1.0 & 30.5 & \\
\hline \multirow[t]{2}{*}{ Japan } & Children & 1.41 & 0.71 & 0.27 & 27.25 & 0.44 & - & - & 1.99 & - & - & Tajima et al. (2014) \\
\hline & Toddler & 9.96 & 5.02 & 1.92 & 193.12 & 2.1 & - & - & 13.44 & - & - & \\
\hline \multirow[t]{2}{*}{ Kuwait } & Adult & - & - & - & - & - & - & - & - & - & 2.55 & Ali et al. (2013) \\
\hline & Toddler & - & - & - & - & - & - & - & - & - & 37.1 & \\
\hline \multirow[t]{2}{*}{ Pakistan } & Adult & - & - & - & - & - & - & - & - & - & 0.18 & Ali et al. (2013) \\
\hline & Toddler & - & - & - & - & - & - & - & - & - & 2.7 & \\
\hline \multirow[t]{2}{*}{ Norway } & Adult (woman) & 4.1 & 0.27 & 0.01 & 0.07 & 0.4 & - & - & 0.03 & 0 & - & Cequier et al. (2014b) \\
\hline & Children & 10 & 0.91 & 0.02 & 1.6 & 1.57 & - & - & 0.06 & 0 & - & \\
\hline \multirow[t]{2}{*}{ South China } & Adult & 1.51 & 0.29 & 0.13 & 0.08 & 0.09 & 0.18 & & 1.36 & 34.5 & 7.02 & He et al. (2015) \\
\hline & Toddler & 17.3 & 3.3 .6 & 1.49 & 0.87 & 1 & 2.1 & - & 15.5 & 3.02 & 80.2 & \\
\hline \multirow[t]{2}{*}{ Egypt } & Adult & 1.2 & 0.8 & 1.6 & 2 & 1 & 0.8 & - & 1.9 & - & 5.2 & Abdallah and Covaci (2014) \\
\hline & Toddler & 3.0 & 1.9 & 4.0 & 5 & 2.6 & 2.1 & - & 4.8 & - & 13 & \\
\hline \multirow[t]{2}{*}{ Philippines } & Adult & - & 0.43 & - & - & 0.24 & 1.4 & 1.8 & 1.1 & 0.23 & - & Kim et al. (2012) \\
\hline & Toddler & - & 1.5 & - & - & 0.82 & 4.7 & 6 & 3.8 & 0.78 & - & \\
\hline \multirow[t]{3}{*}{ UK } & Adult & 0.92 & 0.03 & 0.07 & - & 0.01 & 0.09 & - & 0.13 & - & 1.3 & Brommer and Harrad (2015) \\
\hline & Children & 43 & 1.7 & 4 & - & 0.08 & 14 & - & 7 & - & 70 & \\
\hline & RfD & 8000 & 2200 & 1500 & 1500 & 2400 & - & - & 7000 & - & 22,600 & Van den Eede et al. (2011) \\
\hline
\end{tabular}

detected in indoor environments (Table 2). The OPFR intake rates via inhalation in Sweden $\left(5.8 \mu \mathrm{g} \cdot(\mathrm{kg} \mathrm{d})^{-1}\right.$ for adults and $57 \mu \mathrm{g} \cdot(\mathrm{kg} \mathrm{d})^{-1}$ for children) were larger than those in other countries (Marklund et al., 2005a) but was lower than the reference dose (RfD) of $22.6 \mu \mathrm{g} \cdot(\mathrm{kg} \mathrm{d})^{-1}$ calculated by Van den Eede et al. (2011). These regional differences in exposure are likely driven by differences in the use of consumer products, the frequency of vacuumcleaning and the regulation of indoor materials among these countries (Dishaw et al., 2014; Wei et al., 2015). In these exposure assessments, children and toddlers were considered to be vulnerable groups due to their more frequent hand-to-mouth activities, lower body weights and more time spent at home than adults (Ali et al., 2012; Tajima et al., 2014). Therefore, the intake rates of OPFRs via inhalation for children and toddlers that were reported in these studies were several orders of magnitude higher than the rates reported for adults.

Absorption of OPFRs via diet has also been assessed recently regarding the risk to human health, but data about this route of absorption are sparse. Sundkvist et al. (2010) estimated that the average ingestion of OPFRs for an adult would be $20 \mathrm{ng} \cdot(\mathrm{kg} \mathrm{d})^{-1}$, based on the recommended amount of fish consumption of $375 \mathrm{~g}$ week $^{-1}$ by the National Food Administration. The ingestion rate of OPFRs was $0.67 \mu \mathrm{g} \cdot(\mathrm{kg} \mathrm{d})^{-1}$ for a breastfeeding baby who consumes 1 L of mother's milk per day (Sundkvist et al., 2010). Another assessment of OPFR intake through fish consumption was estimated among the population living along Manila Bay, in which the total dietary intake was $5.9 \mu \mathrm{g} \cdot(\mathrm{kg} \mathrm{d})^{-1}$ for an adult, based on an annual fish consumption of $30 \mathrm{~kg}$ year $^{-1}$ (Kim et al., 2011). However, the total exposure of humans to OPFRs, including all routes of absorption, remains unknown. Hence, for further exposure assessments it is important to consider OPFR concentrations in all pollution sources and the personal habits of the study participants for the population under study.

\section{Bioaccumulation}

\subsection{Bioaccumulation}

Measurements of OPFR biodegradability and bioaccumulation in the environment date back to the 1970s, when OPFRs were recognized to have moderate potential to accumulate in aquatic organisms (Saeger et al., 1979). OPFRs have greater variation in the log Kow range than PBDEs (i.e., log Kow of PBDEs ranges from 4.3 to 9.9 (Van Ael et al., 2013)) and show less bioaccumulation than PBDEs, with bioconcentration factors (BCFs) ranging from 128 to 44,430 (Mansouri et al., 2012). Chlorinated OPFRs generally have relatively lower estimated BCFs than aryl-OPFRs, and BCF increases with molecular mass in non-chlorinated OPFRs (Van der Veen and de Boer, 2012). The OPFRs indicated in the article have a large range of BCFs, from 0.425 for TCEP to $1.00 \times 10^{6}$ for TEHP (Table 1 ). According to the REACH criterion (BCF $\geq 500$; European Union (2008)), aryl-OPFRs, such as TCP, TEHP, EHDPHP, DCP, RDP and TXP can be classified as bioaccumulative compounds (Table 1).

However, the real accumulative potential of OPFRs is variable among different individuals and species (Table 3). Sundkvist et al. (2010) found that total OPFRs levels (e.g., TCIPP, TPHP, TBOEP, TBP, EHDPHP, TCP, TDCIPP) in large perch were higher than in small perch. This finding suggested that larger fishes could accumulate more OPFRs. In different studies of TPHP bioaccumulative potential in fishes, BCFs based on most experimental data were reported to range from 0.06 (in Phoxinus phoxinus) to 2590 (Pimephales promelas) (reviewed by Waaijers et al. (2013)). Wang et al. (2015b) observed that concentrations of TDCIPP in female zebrafish were higher than those in males after OPFRs exposure, indicating gender-dependent bioaccumulation of OPFRs. Differences in feeding behavior and metabolic efficiency between different individuals or species may greatly impact the accumulative potential of OPFRs (Bestvater, 2014; Wang et al., 2015a), but the mechanisms underlying this difference remain unknown. However, what is clear is that many OPFRs (e.g., TCIPP, TPHP, TBOEP, TBP, EHDPHP, TCP, TDCIPP and TEHP) have limited affinity for lipid content in fishes, suggesting that the accumulation of OPFRs is not basically associated with lipids (Brandsma et al., 2015; Chen et al., 2012; Kim et al., 2011; Malarvannan et al., 2015; Sundkvist et al., 2010).

In addition, some prevalent OPFRs in aquatic environments have been detected in most organisms despite their lower BCFs. TCIPP (with a BCF of 8.51) was found at relatively high levels in rainbow trout from Lake Ontario (Bestvater, 2014) and mussels from lakes and coastal areas in Sweden (Sundkvist et al., 2010). In an investigation of the distribution of OPFRs in fishes from Manila Bay, TEP and TBP (with BCFs of 3.16 and 39.81, respectively), in addition to TEHP and EHDPHP (with BCFs of $1.00 \times 10^{6}$ and 855.3, 
Table 3

BCFs (bioconcentration factors) of OPFRs in recent reports.

\begin{tabular}{|c|c|c|c|c|c|c|c|}
\hline \multirow[t]{2}{*}{ Species } & \multicolumn{6}{|c|}{ BCFs for OPFRs } & \multirow[t]{2}{*}{ References } \\
\hline & TCIPP & TCEP & TDCIPP & ТВP & TEHP & TPHP & \\
\hline Goldfish & - & $0.7-0.9$ & $3-5$ & $7-11$ & - & $110-150$ & Sasaki et al. (1981) \\
\hline Killifish & - & 2.2 & $33-113$ & $30-35$ & - & $250-300$ & Sasaki et al. (1981) \\
\hline Cyprinoid fish & $0.8-4.6$ & $0.6-5.1$ & $0.3-22$ & - & - & - & Green et al. (2007); Evenset et al. (2009); Leonards et al. (2010) \\
\hline Fish & - & $1.1-2.2$ & $31-107$ & - & 250 & - & WHO (1998) \\
\hline
\end{tabular}

respectively), were found to have a high body burden due to their greater environmental levels (Kim et al., 2011). Hence, OPFRs with relatively high background levels should be given more attention for the potential threat that they pose to organisms.

\subsection{Biomagnification}

Each organic pollutants transferred differently in the food web as the variation of physico-chemical properties and bioavailability and metabolic transformation for organisms. For OPFRs, the biomagnification factors (BMFs) have only been calculated recently in aquatic food webs. Brandsma et al. (2015) calculated BMFs $>1$ for TBOEP, TCIPP and TCEP (with BMFs of 3.5, 2.2 and 2.6, respectively) in the benthic food web. There was no observed magnification for TDCIPP, TBP, TMPP, EHDPHP, TCP, TBOEP and TEHP. Brandsma et al. (2015) ascribed the trophic magnification in the benthic food web of TBOEP, TCIPP and TCEP to their high levels of emission and their substantial exposure (Brandsma et al., 2015). Kim et al. (2011) confirmed that there was a significant biomagnification for only TPHP in the demersal fishes of Manila Bay, although they had not calculated its BMF. Nevertheless, results of this type are too few to obtain a clear and thorough understanding of the biomagnification of OPFRs in ecosystems, and more investigations are sorely needed.

OPFRs more likely magnify through the benthic food web rather than through the pelagic food web in aquatic environments. Brandsma et al. (2015) observed that OPFRs (TCEP, TCIPP, TDCIPP, TPHP, TBP, TBOEP, EHDPHP and TEHP) demonstrated trophic dilution in the pelagic food web. This was probably because OPFRs were generally adsorbed to particles, and thus were likely to be more abundant in the sediment than in the water column (Brandsma et al., 2015; Kim et al., 2011). Many OPFRs had low levels of trophic biomagnification based on the limited data likely due to metabolism. However, compared with aquatic species, studies on the bioaccumulation of OPFRs in terrestrial food chains are generally scarce, especially in terrestrial avians and mammals, which are also extensively exposed to OPFRs.

For mechanism of OPFRs biomagnification, the studies are still limit to get clear and holistic comprehension. Unlike PBDEs, OPFRs have limited lipid affinity. Beside the studied passive biotransport (e.g., $\log \mathrm{K}_{\mathrm{OW}}$ and bioconcentration factors of OPFRs, lipid and protein content of animal), the direct interactions of specific biomolecules (i.e., various transport proteins) may give new insights into the intrinsic mechanisms. Assessment of the biotransport ability of OPFRs (i.e., BMFs) have tentatively done, however, more works are required to clarify their species-specific risks, which should take into account the specie, size, gender of the test animals and test conditions.

\section{Metabolism}

Metabolism is considered to be a major determinant of the bioaccumulation and clearance of xenobiotics, as well as an indirect determinant of the toxicological effects of these compounds (Meyer and Bester, 2004). The study of metabolic processes is an important component of ecotoxicology and has greatly facilitated our understanding of the fate and mechanisms of toxicity of OPFRs.

\subsection{Metabolic processes}

In metabolism studies, the recently emerged in vivo and in vitro approaches are the most robust and widely used approaches (Van de Waterbeemd and Testa, 2015). In vivo and in vitro OPFR metabolism has been examined in laboratory animals and in humans. Previous studies have demonstrated that OPFRs can be rapidly metabolized through Phase-I and Phase-II biotransformation to metabolites (Table 4), which are more hydrophilic and more readily eliminated (Cooper et al., 2011; Van den Eede et al., 2013a). Although information is still limited, a qualitative summary of the possible metabolic pathways for each type of OPFRs (chlorinated OPFRs, alkyl-OPFRs and aryl-OPFRs) can be proposed (Fig. 2-A-C).

\subsubsection{Chlorinated OPFRs}

Chlorinated OPFRs are the most extensively studied compounds. As early as the 1980s, rodent exposure experiments had been conducted to explore metabolites of TDCIPP and TCEP. Lynn et al. (1981) found that TDCIPP transformed to bis(1,3-dichloro-2propyl) phosphate (BDCIPP), 1,3-dichloro-2-propyl phosphate (MDCIPP) and 1,3-dichloro-2-propanol (1,3-DCP). Nomeir et al. (1981) identified a glutathione-conjugated TDCIPP as a Phase-II metabolite in rat livers in vitro. TCEP can also metabolize to bis (2-chloroethyl) hydrogen phosphate (BCEP), bis (2-chloroethyl) carboxymethyl phosphate and glucuronide of bis (2-chloroethyl) 2hydroxyethyl phosphate in rats (Burka et al., 1991; Sasaki et al., 1984).

The metabolism of chlorinated OPFRs (TDCIPP, TCEP and TCIPP) in human liver preparations was also examined recently (Van den Eede et al., 2013a). Hydroxylated TDCIPP (OH-TDCIPP), carboxylated TDCIPP (COOH-TDCIPP), BDCIPP and hydroxylated BDCIPP (OH-BDCIPP) were all validated as major Phase-I metabolites for TDCIPP. The identified TCEP metabolites included BCEP and hydroxyethyl 2-chloroethyl hydrogen phosphate (OH-TCEP). Similarly, TCIPP metabolized to hydroxylated TCIPP (OH-TCIPP), bis(1chloropropyl) phosphate (BCIPP), hydroxylated BCIPP (OH-BCIPP) and carboxylated TCIPP (COOH-TCIPP). For the Phase-II metabolites, glutathione-conjugated TDCIPP and TCEP were identified in all chlorinated OPFRs, except for TDCIPP (Nomeir et al., 1981; Van den Eede et al., 2013a).

The overall metabolic pathway of chlorinated OPFRs is shown in (Fig. 2-A). The Phase-I metabolic pathway of chlorinated OPFRs involves cleavage of the ether bond (O-dealkylation) and oxidative dehalogenation of the terminal carbon atom. These reactions produce the formation of diesters (DAPs) and hydroxylated metabolites and ultimately form carboxylic acids. In addition, the formation of Phase-II metabolites (glutathione conjugate) can occur through direct substitution of $\mathrm{Cl}$ atoms in chlorinated OPFRs, which are electrophilic or substitutive in molecules. 
Table 4

Summary of major metabolites of OPFRs from recent OPFRs metabolism studies.

\begin{tabular}{|c|c|c|c|c|}
\hline Compounds & Species/assays & Methods & Major metabolites & References \\
\hline \multirow[t]{4}{*}{ TDCIPP } & Rat & In vivo & BDCIPP, MDCIPP, 1,3-DCP, 3-MCPD & Lynn et al. (1981) \\
\hline & Rat liver homogenate & In vitro & BDCIPP, 1,3-DCP, 3-MCPD, glutathione-conjugated TDCIPP & $\begin{array}{l}\text { Nomeir et al. (1981); } \\
\text { Sasaki et al. (1984) }\end{array}$ \\
\hline & $\begin{array}{l}\text { Human liver microsome } \\
\text { (HLM) }\end{array}$ & In vitro & $\begin{array}{l}\text { BDCIPP, hydroxylated TDCIPP (OH-TDCIPP), hydroxylated BDCIPP (OH-BDCIPP), } \\
\text { hydrocarboxylated TDCIPP (COOH-TDCIPP) }\end{array}$ & $\begin{array}{l}\text { Van den Eede et al. } \\
\text { (2013a) }\end{array}$ \\
\hline & Human liver S9 fraction & In vitro & $\begin{array}{l}\text { BDCIPP, hydroxylated TDCIPP (OH-TDCIPP), hydroxylated BDCIPP (OH-BDCIPP), } \\
\text { hydrocarboxylated TDCIPP (COOH-TDCIPP), glutathione-conjugated TDCPP }\end{array}$ & $\begin{array}{l}\text { Van den Eede et al. } \\
(2013 a)\end{array}$ \\
\hline \multirow[t]{4}{*}{ TCEP } & Rat & In vivo & BCEP, hydrocarboxylated TCEP (OH-TCEP), glucuronide-conjugated BCEP & Burka et al. (1991) \\
\hline & $\begin{array}{l}\text { Human liver microsome } \\
\text { (HLM) }\end{array}$ & In vitro & BCEP & Chapman et al. (1991) \\
\hline & $\begin{array}{l}\text { Human liver microsome } \\
\text { (HLM) }\end{array}$ & In vitro & BCEP, hydroxylated TCEP (OH-TCEP) & $\begin{array}{l}\text { Van den Eede et al. } \\
\text { (2013a) }\end{array}$ \\
\hline & Human liver S9 fraction & In vitro & BCEP, hydroxylated TCEP (OH-TCEP), glutathione-conjugateed TCEP & $\begin{array}{l}\text { Van den Eede et al. } \\
\text { (2013a) }\end{array}$ \\
\hline TCIPP & $\begin{array}{l}\text { Human liver microsome } \\
\text { (HLM), human liver S9 } \\
\text { fraction }\end{array}$ & In vitro & $\begin{array}{l}\text { BCIPP, hydroxylated TCIPP (OH-TCIPP), hydrocarboxylated TCIPP (COOH-TCIPP), } \\
\text { hydroxylated BCIPP (OH-BCIPP) }\end{array}$ & $\begin{array}{l}\text { Van den Eede et al. } \\
\text { (2013a) }\end{array}$ \\
\hline \multirow[t]{2}{*}{ TnBP } & Rat & In vivo & DnBP, MnBP, dihydroxylated TnBP (di-OH- TnBP) & Suzuki et al. (1984) \\
\hline & Rat liver microsome & In vitro & DnBP, hydroxylated TnBP (OH-TnBP), dihydroxylated TnBP (di-OH- TnBP) & Sasaki et al. (1984) \\
\hline \multirow[t]{2}{*}{ TBOEP } & $\begin{array}{l}\text { Human liver microsome } \\
\text { (HLM) }\end{array}$ & In vitro & $\begin{array}{l}\text { BBOEP, bis(2-butoxyethyl) hydroxyethyl phosphate (BBOEHEP), hydroxylated TBOEP (1-HO- } \\
\text { TBOEP, 2-HO-TBOEP and 3-HO-TBOEP), hydrocarboxylated TBOEP (COOH-TBOEP) }\end{array}$ & $\begin{array}{l}\text { Van den Eede et al. } \\
\text { (2013a) }\end{array}$ \\
\hline & Human liver S9 fraction & In vitro & $\begin{array}{l}\text { BBOEP, hydroxylated TBOEP (OH-TBOEP), hydrocarboxylated TBOEP (COOH-TBOEP), } \\
\text { glucuronide-conjugate of hydroxylated TBOEP }\end{array}$ & $\begin{array}{l}\text { Van den Eede et al. } \\
\text { (2013a) }\end{array}$ \\
\hline \multirow[t]{4}{*}{ ТPHP } & $\begin{array}{l}\text { Chicken embryonic } \\
\text { hepatocyte }\end{array}$ & In vitro & DPHP, hydroxylated TPHP (OH-TPHP), dihydroxylated TPHP (di-OH-TPHP) & Su et al. (2014) \\
\hline & $\begin{array}{l}\text { Chicken embryonic } \\
\text { hepatocyte }\end{array}$ & In vitro & DPHP, hydroxylated TPHP ( $p$ - and $m$-OH-TPHP), glucuronide-conjugate of $p$ - OH-TPHP & Su et al. (2015) \\
\hline & $\begin{array}{l}\text { Human liver microsome } \\
\text { (HLM) }\end{array}$ & In vitro & $\begin{array}{l}\text { DPHP, MPHP, hydroxylated TPHP (OH-TPHP), dihydroxylated TPHP (di-OH-TPHP), } \\
\text { hydroxylated DPHP (OH-DPHP) }\end{array}$ & $\begin{array}{l}\text { Van den Eede et al. } \\
\text { (2013a) }\end{array}$ \\
\hline & Human liver S9 fraction & In vitro & $\begin{array}{l}\text { glucuronide-conjugate and sulfate-conjugate of } \mathrm{OH}-\mathrm{TPHP} \text {, glucuronide conjugate of di-OH- } \\
\text { TPHP }\end{array}$ & $\begin{array}{l}\text { Van den Eede et al. } \\
\text { (2013a) }\end{array}$ \\
\hline ТРCP & Rat & In vivo & $\begin{array}{l}\text { DPCP, hydroxylated TPCP (OH-TPCP), hydrocarboxylated TPCP (COOH-TPCP), } \\
\text { dihydrocarboxylated TPCP (di-COOH-TPCP) }\end{array}$ & $\begin{array}{l}\text { Kurebayashi et al. } \\
\text { (1985) }\end{array}$ \\
\hline \multirow[t]{2}{*}{ RDP } & Rats, mice and monkeys & In vivo & $\begin{array}{l}\text { resorcinol, diphenyl phosphate (DPHP), hydroxylated DPHP (OH-DPHP), hydroxylated RDP } \\
\text { isomers (OH-RDP, di-OH-RDP) }\end{array}$ & $\begin{array}{l}\text { Freudenthal et al. } \\
(2000)\end{array}$ \\
\hline & $\begin{array}{l}\text { Human liver microsome } \\
\text { (HLM) }\end{array}$ & In vitro & $\begin{array}{l}\text { DPHP, hydroxy-RDP (OH-RDP) and dihydroxy-RDP (di-OH-RDP), glucuronide and sulfate } \\
\text { conjugates of OH-RDP and di-OH-RDP }\end{array}$ & $\begin{array}{l}\text { Ballesteros-Gómez } \\
\text { et al. (2015) }\end{array}$ \\
\hline \multirow[t]{3}{*}{ EHDPHP } & Rat & In vivo & DPHP, MPHP, hydroxylated DPHP (OH-DPHP), phenol & $\begin{array}{l}\text { Nishimaki-Mogami } \\
\text { et al. (1988) }\end{array}$ \\
\hline & $\begin{array}{l}\text { Human liver microsome } \\
\text { (HLM) }\end{array}$ & In vitro & DPHP, hydroxylated EHDPHP, dihydroxylated EHDPHP, & $\begin{array}{l}\text { Ballesteros-Gómez } \\
\text { et al. (2015) }\end{array}$ \\
\hline & Human liver S9 fraction & In vitro & $\begin{array}{l}\text { DPHP, hydroxylated EHDPHP, dihydroxylated EHDPHP, glucuronidate conjugate of } \\
\text { hydroxylated EHDPHP }\end{array}$ & $\begin{array}{l}\text { Ballesteros-Gómez } \\
\text { et al. (2015) }\end{array}$ \\
\hline
\end{tabular}

\subsubsection{Alkyl-OPFRs}

Published information on the metabolism of alkyl-OPFRs exists only for TnBP in laboratory animals and TBOEP in human liver microsomes. Suzuki et al. (1984) studied the metabolism of TnBP in male rats in vivo, in which the major metabolites in urine were dibutyl hydrogen phosphate (DnBP), butyl dihydrogen phosphate (MnBP), butyl bis(3-hydroxybutyl) phosphate (di-OH-TnBP) and other metabolites of hydroxylated derivatives of the butyl moieties. In a study of the metabolism in rat liver microsomes in vitro, TnBP could easily be oxidized to hydroxylated TnBP and further transformed to dihydroxylated TnBP or DnBP (Sasaki et al., 1984). No Phase-II metabolites of TBP have been reported.

In a human liver microsome study, bis(2-butoxyethyl) phosphate (BBOEP), bis(2-butoxyethyl) hydroxyethyl phosphate (BBOEHEP), four isomers of mono-hydroxylated TBOEP (di-OHTBOEP) and some ketone isomers were reported to be metabolites of TBOEP (Van den Eede et al., 2013a). For Phase-II metabolites, a glucuronide conjugate with BBOEHEP was identified in human liver S9 fraction incubation (Van den Eede et al., 2013a). In another study using human liver microsomes, the mono-hydroxylated metabolites of TBOEP were confirmed to be 3-HO-TBOEP (bis(2butoxyethyl) 3-hydroxyl-2-butoxyethyl phosphate), 1-HO-TBOEP (bis(2-butoxyethyl) 1-hydroxyl-2-butoxyethyl phosphate) and 2HO-TBOEP (bis(2-butoxyethyl) 1-hydroxyl-2-butoxyethyl phosphate) (Van den Eede et al., 2015a).

Alkyl-OPFRs, as with the chlorinated compounds, were also thought to be easily dealkylated to their respective diesters via hydrolysis. Hydroxylation of unsubstituted carbon atoms has been shown to occur in alkyl-OPFR, instead of oxidative dehalogenation in chlorinated OPFR metabolism. Hydroxylation was more likely to occur on the terminal carbon atoms for alkyl-OPFRs, which would be more stable than hydroxylation on other carbon atoms (Van den Eede et al., 2015a). Moreover, further hydroxylation, hydrocarboxylation or oxidative dealkylation also partially occurred in the former metabolites of these compounds (Fig. 2-B). Overall, the formation of Phase-II metabolites occurred on hydroxyls formed in Phase-I metabolism, and the formation of these metabolites was distinct from that of chlorinated OPFRs.

\subsubsection{Aryl-OPFRs}

As for aryl-OPFRs, metabolites of TCP, TPHP and resorcinol bisdiphenylphosphate (RDP) were investigated in laboratory animals. Kurebayashi et al. (1985) studied the metabolism of TCP in rats. In this study, the major metabolites were $p$-hydroxybenzoic acid, di-p-cresyl phosphate (DCP), $p$-cresyl $p$-carboxyphenyl phosphate (COOH-TCP) and $p$-cresyl di-p-carboxyphenyl phosphate (diCOOH-TCP). Su et al. (2014) studied the metabolism of TPHP in chicken embryonic hepatocytes in vitro. The identified metabolites 
Cl-contained OPFRs

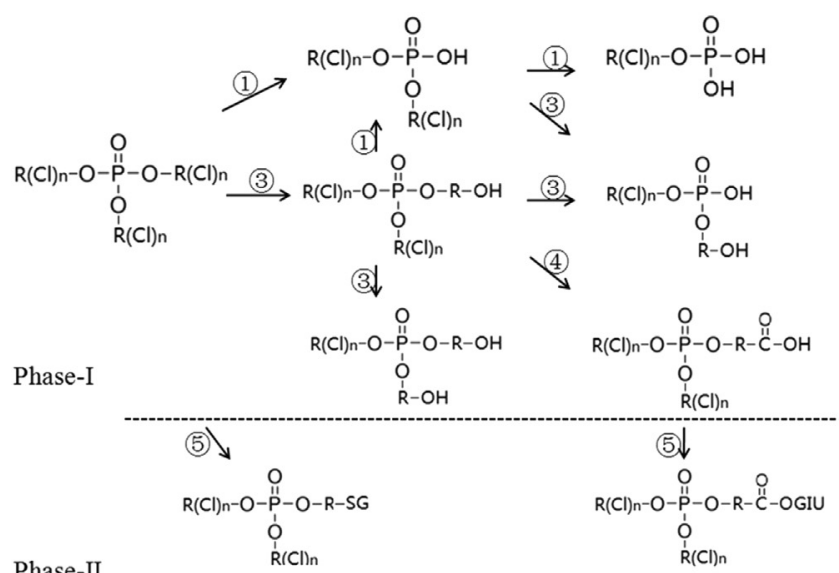

A

Alkyl-OPFRs

Aryl-OPFRs

C

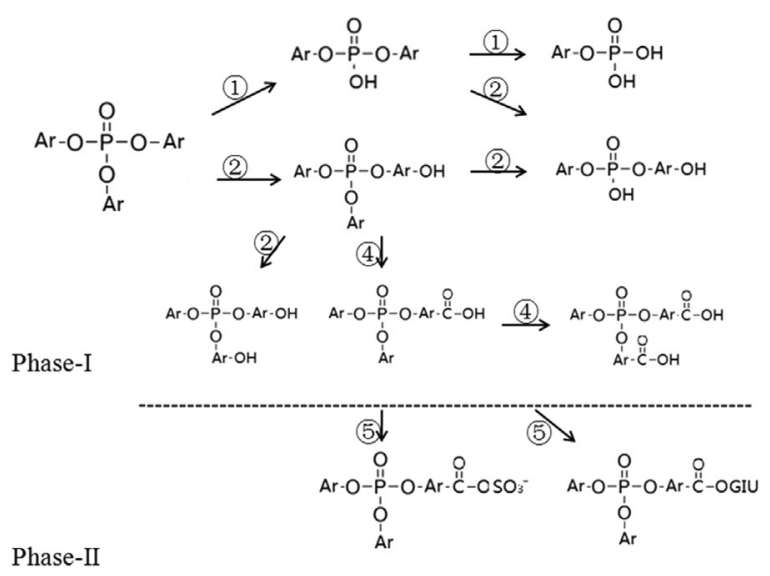

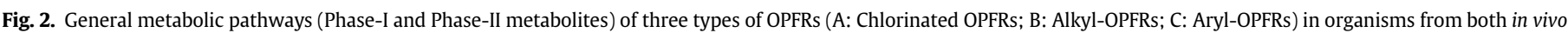

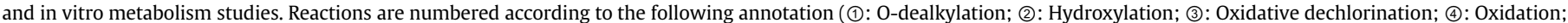
(5): Conjugation).

were DPHP, hydroxylated TPHP (OH-TPHP) and dihydroxylated TPHP isomers (di-OH-TPHP). Su et al. (2015) then identified the hydroxylated TPHP as $p$ - and $m$-OH-TPHP and found that the conjugate with glucuronic was primarily on $p-\mathrm{OH}-\mathrm{TPHP}$. RDP, which is a structure analogous to TPHP, has been studied only in rats, mice and monkeys in vivo (Freudenthal et al., 2000). The major excreted metabolites were resorcinol, diphenyl phosphate (DPHP), hydroxylated DPHP (OH-DPHP), and hydroxylated RDP isomers (OH-RDP, di-OH-RDP). No differences were observed between species.

To date, the metabolism of TPHP and RDP has also been studied in human liver microsomes in vitro. In addition to the metabolites in the aforementioned chicken hepatocytes, mono-ester (MPHP) and hydroxylated DPHP (OH-DPHP) have also been identified in the metabolism of TPHP (Van den Eede et al., 2013a). Glucuronide conjugates and sulfate conjugates of TPHP were observed in the human liver S9 fractions in the in vitro study of Phase-II metabolites (Van den Eede et al., 2013a). Ballesteros-Gómez et al. (2015) reported the in vitro metabolism of RDP using human liver microsomes, which was consistent with the in vivo metabolism study. RDP was similarly metabolized to DPHP, hydroxy-RDP (OH-RDP) and dihydroxy-RDP (di-OH-RDP) and to glucuronide and sulfate conjugates.
A general metabolic pathway of aryl-OPFRs was same as alkylOPFRs (Fig. 2-C). The Phase-I metabolic processes included hydroxylation, dihydroxylation and carboxylation on the phenyl. Glucuronide and sulfate can only react on hydroxylated or dihydroxylated metabolites in Phase-II reaction. What worth mentioning is EHDPHP, who owns both alkyl and aryl. NishimakiMogami et al. (1988) investigated the in vivo metabolism of EHDPHP on rats by oral exposure. DPHP, phenol and a small quantity of $p$-hydroxyphenyl phenyl phosphate ( $p$-OH-DPHP) and monophenyl phosphate (MPHP) were identified to be major metabolites. While in a EHDPHP study in human liver microsomes in vitro, hydroxylation occurred both in 2-butoxyethyl and phenyl, which formed hydroxylated and dihydroxylated metabolites $(\mathrm{OH}-$ TPHP, di-OH-TPHP). Moreover, DPHP and glucuronidated conjugates of Phase-I metabolites were also detected as the major PhaseI and Phase-II metabolites (Ballesteros-Gómez et al., 2015).

Based on the former studies, a general metabolic pathway of OPFRs includes O-dealkylation, hydroxylation, carboxylation and oxidative dehalogenation (only for chlorinated OPFRs), resulting in a wide array of dialkyl phosphates (DAPs) and hydroxylated and carboxylated metabolite isomers (Table 4). The dehalogenation in all chlorinated OPFRs was driven by oxidation (a replacement of $\mathrm{Cl}$ 
with $\mathrm{OH}$ ), which was different from PBDEs, where reductive dehalogenation pathways were more common (Hakk and Letcher, 2003). Further hydrolysis and oxidation of the alkyl- and arylmoieties were also possible (Kurebayashi et al., 1985). However, the common occurrence of methoxylation in PBDEs has never been reported to occur in OPFR metabolism (Van den Eede et al., 2013a). More likely, these metabolites can be further metabolized to secondary metabolites by dihydroxylation, oxidation of the hydroxylated carbon atom and further O-dealkylation (producing more hydrophilic metabolites). Alternatively, these metabolites can be conjugated with sulfate, glutathione or glucuronic acid (producing Phase-II metabolites), which renders these metabolites much more soluble for elimination (Van den Eede et al., 2013a). Generally, there have been some inconsistencies in the metabolites identified between study approaches (in vivo and in vitro) and between species (Table 4). Nomeir et al. (1981) hypothesized that the in vitro metabolites identified in studies may be further metabolized before being excreted, thereby making them undetectable in some in vivo assays. Different species (rodent, human), matrices (urine, liquid supernatant) and analytical techniques (low or high resolution mass spectrometry) may also be responsible for the inconsistent results (Ballesteros-Gómez et al., 2015).

\subsection{Kinetics of metabolism}

OPFRs can be metabolized through Phase-I and Phase-II biotransformation to metabolites that are more hydrophilic and more readily eliminated (Van den Eede et al., 2013a). OPFRs possess much lower $t_{1 / 2}$ (Table 5) than PBDEs (25d-115d in rat) (Hakk and Letcher, 2003). In general, the OPFRs with the lowest bioaccumulation potential $\left(\log \mathrm{K}_{\mathrm{OW}}<3\right)$ have a higher speed of elimination and shorter half-life $\left(t_{1 / 2}\right)$ in organisms (Green et al., 2007). Sasaki et al. (1981) reported that chlorinated OPFRs (TDCIPP and TCEP) have rapid elimination rates compared with TBP and TPHP in fish. However, among chlorinated OPFRs, Minegishi et al. (1988) considered di-chlorinated OPFRs (TDCIPP) to be the more slowly absorbed, distributed and excreted than the monochlorinated compounds (TCEP and TCIPP).

In many studies of OPFR metabolism conducted in exposed laboratory rodents, urine, feces or expired gas has been assumed to be the main carrier of the excreted metabolites (Table 5). After administration of 14C-TDCIPP in rats, Lynn et al. (1981) found that $92 \%$ of $14 \mathrm{C}$ had been excreted in the urine (54\%), feces $(16 \%)$, and expired air (22\% as $\left.14 \mathrm{CO}_{2}\right)$, where $63 \%$ of TDCIPP was recovered as $\mathrm{BDCIPP}$. This high recovery rate may be due to the fact that BDCIPP has a slow metabolic rate in the body and can be directly eliminated by excretion before being metabolized. In another similar study, after $168 \mathrm{~h}$ of oral exposure to 14C-TDCPP, recovery of $43.2 \%$ of $14 \mathrm{C}$ in urine, $39.2 \%$ in feces and $16.2 \%$ in expired air (Minegishi et al.,
1988). Burka et al. (1991) studied TCEP exposure in rats and mice. They found that more than $70 \%$ of oral-dosed $14 \mathrm{C}$-labelled metabolites were excreted in urine within $8 \mathrm{~h}$, and BCEP was found to be a major metabolite.

Su et al. (2015) most recently studied TPHP metabolism in chicken embryonic hepatocytes in vitro. In this study, the detected p-OH-TPHP (after $\beta$-glucuronidase treatment) accounted for $60 \%$ of the initial TPHP dose at $36 \mathrm{~h}$, which was 3.5-fold higher than that detected for DPHP and 12-fold higher than that detected for $m-\mathrm{OH}$ TPHP. They suggested that the glucuronic acid conjugate of $p-\mathrm{OH}-$ TPHP may serve as a more critical metabolite than the formerly accepted DPHP. However, because of the large time span and the limited magnitude of the reviewed studies, we cannot determine clear differences of OPFRs metabolites rates among individuals, sexes and species.

Crump et al. (2012) have mentioned that some metabolites of OPFRs are comparatively more stable than their parent compounds in the body; hence, some of the adverse effects of OPFRs may, in fact, be the result of their metabolites. Meeker et al. (2013a) reported a significant or suggestive relationship between two urinary OPFR metabolites (BDCIPP and DPHP) and serum hormone levels in men. 1,3-DCP, the metabolite of TDCIPP, has been verified to be a powerful direct-acting mutagen (Gold et al., 1978). DPHP has been reported to alter transcripts associated with the lipid/cholesterol metabolism in chicken embryonic hepatocytes (Su et al., 2014). However, although some kinetic data on absorption and exertion are available, available toxicokinetic studies of OPFRs are still scarce. Toxicokinetics models, which can establish relationships between dosage, bioaccumulation, metabolism and clearance utilizing dose-response measurements (Mošat' et al., 2013), may be a promising direction for future research. Therefore, studies that fully characterize the toxicokinetics of OPFR metabolism and measure circulating and excreted metabolites are sorely needed for the study of OPFR toxicokinetics.

\subsection{Enzymes in metabolism}

The overall evidence from aforementioned studies suggests that multiple metabolic systems may manage the metabolism of OPFRs. Enzyme catalysis is acknowledged to be largely responsible for the metabolism of drugs. The same is likely to be the case for OPFRs, as their metabolism primarily occurs in the liver, kidney, and adipose tissue (Sasaki et al., 1984).

Cytochromes P450 (CYP) was thought to play a critical role in several steps of Phase-I metabolism. For OPFRs metabolic processes, the major CYPs that catalyzed Phase-I reactions were hydroxylation of unsubstituted carbon atoms, O-dealkylationhase-II reactions, and possible mono- and di-hydroxylated Phase-I metabolites (Ballesteros-Gómez et al., 2015). Although CYPs appear to

Table 5

Toxicokinetic studies of OPFRs in laboratory animals.

\begin{tabular}{|c|c|c|c|c|c|c|}
\hline Compounds & Species & Exposure approaches & Major disposition tissues & $\mathrm{t}_{1 / 2}$ & Excretion pathway and proportion & References \\
\hline \multirow[t]{2}{*}{ TDCIPP } & Killifish & Water exposure & - & $31 \mathrm{~h}$ & - & Sasaki et al. (1981) \\
\hline & Goldfish & Water exposure & - & $42 \mathrm{~h}$ & - & Sasaki et al. (1981) \\
\hline \multirow[t]{3}{*}{ TCEP } & Killifish & Water exposure & - & $0.7 \mathrm{~h}$ & - & Sasaki et al. (1981) \\
\hline & Mice & Oral & - & - & Urine $(70 \%)$ & Burka et al. (1991) \\
\hline & Rat & Oral & Liver, kidney, adipose tissue, spleen, lung & $\mathrm{n} / \mathrm{a}$ & Urine (96\%), feces (6\%), expired air (2\%) & Minegishi et al. (1988) \\
\hline \multirow[t]{2}{*}{ TBP } & Killifish & Water exposure & - & $58 \mathrm{~h}$ & - & Sasaki et al. (1981) \\
\hline & Goldfish & Water exposure & - & $>100 \mathrm{~h}$ & - & Sasaki et al. (1981) \\
\hline TEHP & Rat & Inhalation & Lungs, stomach contents, brain and liver & $\mathrm{n} / \mathrm{a}$ & Urine (low), feces (high) & WHO (2000) \\
\hline \multirow[t]{4}{*}{ ТPHP } & Rainbow trout & - & - & $79 \mathrm{~h}$ & - & Green et al. (2007) \\
\hline & Chironomus & - & - & $30-79 \mathrm{~h}$ & - & Green et al. (2007) \\
\hline & Killifish & Water exposure & - & $5 \mathrm{~h}$ & - & Sasaki et al. (1981) \\
\hline & Goldfish & Water exposure & - & $>100 \mathrm{~h}$ & - & (Sasaki et al. (1981)) \\
\hline
\end{tabular}


be the main family of enzymes responsible for the formation of Phase-I metabolites, some hydrolysed metabolites may be catalyzed by NADPH independent liver microsomal phosphatase enzymes, such as, for example, paraoxonases and aryl esterases (Van den Eede et al., 2013a). However, the role of CYPs is likely to be more significant than that of the hydrolases in the these processes, such as O-dealkylationhase-II reactions via the hydroxylation metabolic pathway (Chapman et al., 1991; Sasaki et al., 1984; Van den Eede et al., 2013a). In Phase-II reactions, the conjugating enzymes consist of many superfamilies of enzymes, including glucuronyl transferases (UGTs), sulfotransferases (SULTs) and gluathione S-transferases (GSTs) (Van den Eede et al., 2013a).

\section{Internal exposure}

OPFRs are emerging contaminants, thus, internal exposure to OPFRs is a critical concern. In contrast to external exposure, which concerns the source or pathway to the body, studies of internal exposure have focused on the total concentration of circulatory OPFRs and their metabolites within the body, which indicates the total burden of exposure (Alves et al., 2014).

OPFRs can be transported in the plasma and be distributed through the body and metabolized in liver. OPFRs have been found in various tissues in rodents, fishes and avians. OPFRs are considered to have a weak correlation with lipid content in tissues, which is different from observations of PBDEs (Brandsma et al., 2015; Chen et al., 2012; Greaves and Letcher, 2014; Kim et al., 2011; Sundkvist et al., 2010). For wild animals exposed to OPFRs at the environment level, the contaminants are highly distributed in metabolically inactive tissues, such as adipose tissue, muscle and feathers. Thus, these OPFRs could be transferred to eggs in ova (Evenset et al., 2009). Greaves and Letcher (2014) found that the effect of hydrophobicity was weak with respect to OPFR accumulation in the body of herring gulls. They concluded that other processes, such as metabolism, may play a critical role in the distribution of OPFRs. In the herring gulls of the Great Lakes, metabolically inactive tissues, such as fat, egg yolk, egg albumin, muscle and red blood cells, contained relatively higher OPFR concentrations, whereas no OPFRs were detected in the liver and plasma (Greaves and Letcher, 2014). In surveys of white-tailed eagle nestlings in Norway, the levels of OPFRs detected in feathers were much higher than those detected in other tissues (Eulaers et al., 2014).

When estimating internal burdens of OPFRs in wild animals, the sampling matrices should be fully considered. Plasma can equilibrate with internal tissues and can be easily and non-destructively sampled. Thus, plasma is commonly used as sampling matrice to represent the internal body burden of OPFRs (Eulaers et al., 2014). In the aforementioned studies, OPFRs tend to accumulate in storage organs or metabolically inactive tissues, such as fat, egg and feather. Thus, these tissues may serve as more valuable alternatives or complementary sampling matrices for the conventional analysis of homogenates and muscle samples of animals (Greaves and Letcher, 2014) (SI Table S1). In human biomonitoring, non-invasive matrices are required. Aside from plasma, urine, saliva and hand wipes are the most frequently used matrices in human biomonitoring (Alves et al., 2014; Hoffman et al., 2015; Meeker et al., 2013b). Hair and nails are less metabolically active tissues that may also be promising samples for internal exposure studies (Alves et al., 2014).

OPFR diesters (DAPs) and monoesters (MAPs) are thought to be the major metabolites of many OPFRs, their distribution and concentrations throughout the body would be highly valuable information for understanding the pharmacokinetics of OPFR interactions in the body (Greaves and Letcher, 2014). Recently, quantified DAPs and MAPs in urine have been identified as biomarkers to assess human exposure. In total, DAPs of BDCIPP, BCIPP, BCEP, BBOEP, DBP, DPHP, DEHP and some MAPs of MEHP, MBP, MCIPP, MBOEP and MPHP have been quantified in human urine, with median concentrations in the $\mathrm{ng} \mathrm{ml}^{-1}$ range (Butt et al., 2014; Cequier et al., 2014b, 2015; Chu et al., 2011; Cooper et al., 2011; Dodson et al., 2014; Fromme et al., 2014; Hoffman et al., 2015; Meeker et al., 2013a,b; Moller et al., 2004; Petropoulou et al., 2016; Reemtsma et al., 2011; Schindler et al., 2009a,b; Van den Eede et al., 2015b; Van den Eede et al., 2013b) (SI Table S2). However, no information is available for DAPs and MAPs or other OPFR metabolites from internal exposure studies of wild animals. Quantitative whole-body autoradiography (QWBA) or whole-body autoradioluminography (WBAL) may provide a good solution for the characterization of OPFR burdens and their metabolites throughout the body.

\section{Conclusion}

The wide use of OPFRs and their ubiquitous occurrence in environments has increased their exposure to organisms. An overview of OPFR fates in animals and humans is provided in Fig. 1. Generally, ingestion, inhalation and dermal contact are more important absorption routes for humans, whereas ingestion is more important for wildlife exposed to OPFRs. After being absorbed, OPFRs can accumulate in the body, depending on their physicochemical properties and exposure levels. It is further suggested that OPFRs can be transferred through aquatic and terrestrial food chains, but to our knowledge there are no clear conclusion that OPFRs can biomagnify in food webs. Assessment of the bioaccumulation and biomagnification of OPFRs (BCFs and BMFs, respectively) have tentatively done, however, more works are required to clarify their species-specific risks, which should take into account the specie, size, gender of the test animals.

The common metabolic pathways are summarized for all three types of OPFRs (chlorinated OPFRs, alkyl-OPFRs and aryl-OPFRs), including O-dealkylation, hydroxylation and oxidative dehalogenation. Studies on OPFR metabolism have been limited to laboratory rats and in vitro human models. There is no information on the in vivo metabolic process of OPFRs on other wildlife. Using advanced analysis methods (i.e., UPLC-QTOF-MS with targeted and untargeted screening tools), more in vivo studies can be conducted to identify a wide variety of metabolites to provide confirmation that metabolism of OPFRs readily occurs in organisms. For the study of OPFRs metabolism, in silico models can be used to identify the metabolites formed to simplify the screening process. Combinations of in vitro and in silico methods, which have been called the in combo approach, may be the most promising strategy for studies of metabolism.

In recent studies, investigators have mainly focused on DAPs and MAPs as major biomarkers in urine for internal studies of human. However, information about the other in vivo Phase-I or Phase-II metabolites (i.e., hydroxylated metabolites, glucuronic and sulfate conjugates) was less available in human excreta monitoring reports. For exposure assessments of wild animals, only residual OPFRs were analyzed in the plasma or in different tissues. The major OPFR metabolites formed in in vitro studies are valuable candidate markers for monitoring wild animal exposure (Alves et al., 2014). Future research focusing on the quantification of more OPFRs and their metabolites in other metabolically inactive tissues may provide a comprehensive picture of the internal exposure of OPFRs in animals and humans.

\section{Acknowledgement}

This work is supported by the National Natural Science 
Foundation of China (No. 21437006, No. 51290283).

\section{Appendix A. Supplementary data}

Supplementary data related to this article can be found at http:// dx.doi.org/10.1016/j.chemosphere.2016.03.003.

\section{References}

Abdallah, M.A., Covaci, A., 2014. Organophosphate flame retardants in indoor dust from Egypt: implications for human exposure. Environ. Sci. Technol. 48, 4782-4789.

Ali, N., Ali, L., Mehdi, T., Dirtu, A.C., Al-Shammari, F., Neels, H., Covaci, A., 2013. Levels and profiles of organochlorines and flame retardants in car and house dust from Kuwait and Pakistan: implication for human exposure via dust ingestion. Environ. Int. 55, 62-70.

Ali, N., Dirtu, A.C., Van den Eede, N., Goosey, E., Harrad, S., Neels, H., t Mannetje, A., Coakley, J., Douwes, J., Covaci, A., 2012. Occurrence of alternative flame retardants in indoor dust from New Zealand: indoor sources and human exposure assessment. Chemosphere 88, 1276-1282.

Alves, A., Kucharska, A., Erratico, C., Xu, F., Den Hond, E., Koppen, G., Vanermen, G., Covaci, A., Voorspoels, S., 2014. Human biomonitoring of emerging pollutants through non-invasive matrices: state of the art and future potential. Anal. Bioanal. Chem. 406, 4063-4088.

Andresen, J.A., Grundmann, A., Bester, K., 2004. Organophosphorus flame retardants and plasticisers in surface waters. Sci. Total Environ. 332, 155-166.

Bacaloni, A., Cucci, F., Guarino, C., Nazzari, M., Samperi, R., Lagana, A., 2008. Occurrence of organophosphorus flame retardant and plasticizers in three volcanic lakes of central Italy. Environ. Sci. Technol. 42, 1898-1903.

Ballesteros-Gómez, A., Erratico, C.A., Eede, N.V.d., Ionas, A.C., Leonards, P.E.G., Covaci, A., 2015. In vitro metabolism of 2-ethylhexyldiphenyl phosphate (EHDPHP) by human liver microsomes. Toxicol. Lett. 232, 203-212.

Benotti, M.J., Trenholm, R.A., Vanderford, B.J., Holady, J.C., Stanford, B.D., Snyder, S.A., 2009. Pharmaceuticals and endocrine disrupting compounds in U.S. drinking water. Environ. Sci. Technol. 43, 597-603.

Bestvater, L.L., 2014. The Persistence, Bioaccumulation, and Inherent Toxicity of Two Organophosphate Flame Retardants Tris (2-butoxyethyl) Phosphate and Tris (1chloro-2-propyl) Phosphate in Juvenile Rainbow Trout (Oncorhynchus mykiss). University of Manitoba.

Brandsma, S.H., Leonards, P.E.G., Leslie, H.A., de Boer, J., 2015. Tracing organophosphorus and brominated flame retardants and plasticizers in an estuarine food web. Sci. Total Environ. 505, 22-31.

Brommer, S., Harrad, S., 2015. Sources and human exposure implications of concentrations of organophosphate flame retardants in dust from UK cars, classrooms, living rooms, and offices. Environ. Int. 83, 202-207.

Brommer, S., Harrad, S., Van den Eede, N., Covaci, A., 2012. Concentrations of organophosphate esters and brominated flame retardants in German indoor dust samples. J. Environ. Monit. JEM 14, 2482-2487.

Burka, L.T., Sanders, J.M., Herr, D.W., 1991. Metabolism of tris (2-chloroethyl) phosphate in rats and mice. Drug Metab. Dispos. 2, 443-447.

Butt, C.M., Congleton, J., Hoffman, K., Fang, M., Stapleton, H.M., 2014. Metabolites of organophosphate flame retardants and 2-ethylhexyl tetrabromobenzoate in urine from paired mothers and toddlers. Environ. Sci. Technol. 48, 10432-10438.

Campone, L., Piccinelli, A., Östman, C., Rastrelli, L., 2010. Determination of organophosphorous flame retardants in fish tissues by matrix solid-phase dispersion and gas chromatography. Anal. Bioanal. Chem. 397, 799-806.

Carlsson, H., Nilsson, U., Östman, C., 2000. Video display units: an emission source of the contact allergenic flame retardant triphenyl phosphate in the indoor environment. Environ. Sci. Technol. 34, 3885-3889.

Cequier, E., Ionas, A.C., Covaci, A., Marcé, R.M., Becher, G., Thomsen, C., 2014a. Occurrence of a broad range of legacy and emerging flame retardants in indoor environments in Norway. Environ. Sci. Technol. 48, 6827-6835.

Cequier, E., Marcé, R.M., Becher, G., Thomsen, C., 2014b. A high-throughput method for determination of metabolites of organophosphate flame retardants in urine by ultra performance liquid chromatography-high resolution mass spectrometry. Anal. Chim. Acta 845, 98-104.

Cequier, E., Sakhi, A.K., Marcé, R.M., Becher, G., Thomsen, C., 2015. Human exposure pathways to organophosphate triesters - a biomonitoring study of mother-child pairs. Environ. Int. 75, 159-165.

Chapman, D.E., Michener, S.R., Powis, G., 1991. Metabolism of the flame retardant plasticizer tris(2-chloroethyl)phosphate by human and rat liver preparations. Fundam. Appl. Toxicol. 17, 215-224.

Chemspider, [Cited 16 May 2015], Available from: http://www.chemspider.com/ Search.aspx.

Chen, D., Letcher, R.J., Chu, S., 2012. Determination of non-halogenated, chlorinated and brominated organophosphate flame retardants in herring gull eggs based on liquid chromatography-tandem quadrupole mass spectrometry. J. Chromatogr. A 1220, 169-174.

Chu, S., Chen, D., Letcher, R.J., 2011. Dicationic ion-pairing of phosphoric acid diesters post-liquid chromatography and subsequent determination by electrospray positive ionization-tandem mass spectrometry. J. Chromatogr. A 1218,
8083-8088.

Chung, H.W., Ding, W.H., 2009. Determination of organophosphate flame retardants in sediments by microwave-assisted extraction and gas chromatography-mass spectrometry with electron impact and chemical ionization. Anal. Bioanal. Chem. 395, 2325-2334.

Cooper, E.M., Covaci, A., Van Nuijs, A.L.N., Webster, T.F., Stapleton, H.M., 2011 Analysis of the flame retardant metabolites bis(1,3-dichloro-2-propyl) phosphate (BDCPP) and diphenyl phosphate (DPP) in urine using liquid chromatography-tandem mass spectrometry. Anal. Bioanal. Chem. 401, 2123-2132.

Cristale, J., Katsoyiannis, A., Sweetman, A.J., Jones, K.C., Lacorte, S., 2013. Occurrence and risk assessment of organophosphorus and brominated flame retardants in the River Aire (UK). Environ. Pollut. 179, 194-200.

Crump, D., Chiu, S., Kennedy, S.W., 2012. Effects of tris(1,3-dichloro-2-propyl) phosphate and tris(1-chloropropyl) phosphate on cytotoxicity and mRNA expression in primary cultures of avian hepatocytes and neuronal cells. Toxicol. Sci. 126, 140-148.

Dishaw, L.V., Hunter, D.L., Padnos, B., Padilla, S., Stapleton, H.M., 2014. Developmental exposure to organophosphate flame retardants elicits overt toxicity and alters behavior in early life stage zebrafish (Danio rerio). Toxicol. Sci. 142, 445-454.

Dishaw, L.V., Powers, C.M., Ryde, I.T., Roberts, S.C., Seidler, F.J., Slotkin, T.A. Stapleton, H.M., 2011. Is the PentaBDE replacement, tris (1,3-dichloro-2-propyl) phosphate (TDCPP), a developmental neurotoxicant? Studies in PC12 cells. Toxicol. Appl. Pharmacol. 256, 281-289.

Dodson, R.E., Van den Eede, N., Covaci, A., Perovich, L.J., Brody, J.G., Rudel, R.A., 2014 Urinary biomonitoring of phosphate flame retardants: levels in California adults and recommendations for future studies. Environ. Sci. Technol. 48, $13625-13633$.

Du, Z., Wang, G., Gao, S., Wang, Z., 2015. Aryl organophosphate flame retardants induced cardiotoxicity during zebrafish embryogenesis: by disturbing expression of the transcriptional regulators. Aquat. Toxicol. 161, 25-32.

EFRA, 2007. Flame Retardants Frequently Asked Questions. The European Flame Retardants Association, Brussels.

EPA, 2005. Environmental Profiles of Chemical Flame-retardant Alternatives for Low-density Polyurethane Foam. United States Environmental Protection Agency, U S.

Eulaers, I., Jaspers, V.L.B., Halley, D.J., Lepoint, G., Nygård, T., Pinxten, R., Covaci, A., Eens, M., 2014. Brominated and phosphorus flame retardants in white-tailed eagle Haliaeetus albicilla nestlings: bioaccumulation and associations with dietary proxies ( $\delta 13 \mathrm{C}, \delta 15 \mathrm{~N}$ and $\delta 34 \mathrm{~S}$ ). Sci. Total Environ. 478, 48-57.

European Union, 2008. European Union Risk Assessment Report: Tris (1-chloro-2propyl) Phosphate (TCPP). EINECS No: 237-158-7. Office for Official Publications of the European Communities, Luxembourg.

European Union Commision Directive, 2014. Commission directive 2014/2081/EU of 2023 June 2014. Off. J. Eur. Union L2183, 2049-2051.

Evenset, A., Leknes, H., Christensen, G.N., Warner, N., Remberger, M., Gabrielsen, G.W., 2009. Screening of New Contaminants in Samples from the Norwegian Arctic Rapport. Akvaplan-niva Report. Norwegian Pollution Control Agency, Norway.

Freudenthal, R.I., McDonald, L.J., Johnson, J.V., McCormick, D.L., Henrich, R.T., 2000. Comparative metabolism and toxicokinetics of 14C-resorcinoi bisdiphenylphosphate (RDP) in the rat, mouse, and monkey. Int. J. Toxicol. 19, 233-242.

Fromme, H., Lahrz, T., Kraft, M., Fembacher, L., Mach, C., Dietrich, S., Burkardt, R., Völkel, W., Göen, T., 2014. Organophosphate flame retardants and plasticizers in the air and dust in German daycare centers and human biomonitoring in visiting children (LUPE 3). Environ. Int. 71, 158-163.

Gao, Z., Deng, Y., Yuan, W., He, H., Yang, S., Sun, C., 2014. Determination of organophosphorus flame retardants in fish by pressurized liquid extraction using aqueous solutions and solid-phase microextraction coupled with gas chromatography-flame photometric detector. J. Chromatogr. A 1366, 31-37.

Gold, M.D., Blum, A., Ames, B.N., 1978. Another flame retardant, tris-(1,3-dichloro-2propyl)-phosphate, and its expected metabolites are mutagens. Sci. New York N. Y. 200, 785-787.

Greaves, A.K., Letcher, R.J., 2014. Comparative body compartment composition and in ovo transfer of organophosphate flame retardants in North American Great Lakes herring gulls. Environ. Sci. Technol. 48, 7942-7950.

Green, N., Schlabach, M., Bakke, T., Brevik, E.M., Dye, C., Herzke, D., Huber, S., 2007. Screening of Selected Metals and New Organic Contaminants 2007. Akvaplanniva report. Norwegian Pollution Control Agency, Norway.

Hakk, H., Letcher, R.J., 2003. Metabolism in the toxicokinetics and fate of brominated flame retardants-a review. Environ. Int. 29, 801-828.

He, C.T., Zheng, J., Qiao, L., Chen, S.J., Yang, J.Z., Yuan, J.G., Yang, Z.Y., Mai, B.X., 2015. Occurrence of organophosphorus flame retardants in indoor dust in multiple microenvironments of southern China and implications for human exposure. Chemosphere 133, 47-52.

Hoffman, K., Garantziotis, S., Birnbaum, L.S., Stapleton, H.M., 2015. Monitoring indoor exposure to organophosphate flame retardants: hand wipes and house dust. Environ. Health Perspect. 123 (122).

Kim, J.-W., Isobe, T., Malarvannan, G., Sudaryanto, A., Chang, K.-H., Prudente, M., Tanabe, S., 2012. Contamination of benzotriazole ultraviolet stabilizers in house dust from the Philippines: implications on human exposure. Sci. Total Environ. 424, 174-181.

Kim, J.W., Isobe, T., Chang, K.H., Amano, A., Maneja, R.H., Zamora, P.B., Siringan, F.P. 
Tanabe, S., 2011. Levels and distribution of organophosphorus flame retardants and plasticizers in fishes from Manila Bay, the Philippines. Environ. Pollut. 159, 3653-3659.

Kurebayashi, H., Tanaka, A., Yamaha, T., 1985. Metabolism and disposition of the flame retardant plasticizer, tri-p-cresyl phosphate, in the rat. Toxicol. Appl. Pharmacol. 77, 395-404.

Leonards, P., Steindal, E.H., Van der Veen, I., Berg, V., Bustnes, J.O., Van Leeuwen, S., 2010. Screening of Organophosphor Flame Retardants 2010. Akvaplan-niva report. Norwegian Climate and Pollution Agency, Norway.

Li, J., Yu, N., Zhang, B., Jin, L., Li, M., Hu, M., Zhang, X., Wei, S., Yu, H., 2014. Occurrence of organophosphate flame retardants in drinking water from China. Water Res. 54, 53-61.

Liu, X., Ji, K., Choi, K., 2012. Endocrine disruption potentials of organophosphate flame retardants and related mechanisms in H295R and MVLN cell lines and in zebrafish. Aquat. Toxicol. 114-115, 173-181.

Lynn, R.K., Wong, K., Garvie-Gould, C., Kennish, J.M., 1981. Disposition of the flame retardant, tris(1,3-dichloro-2-propyl) phosphate, in the rat. Drug Metab. Dispos. 9, 434-441.

MacFarland, H.N., Punte Jr., C.L., 1966. Toxicological studies on tri-(2-ethylhexyl)phosphate. Arch. Environ. Health 13, 13-20.

Malarvannan, G., Belpaire, C., Geeraerts, C., Eulaers, I., Neels, H., Covaci, A., 2015. Organophosphorus flame retardants in the European eel in Flanders, Belgium: occurrence, fate and human health risk. Environ. Res. 140, 604-610.

Mansouri, K., Consonni, V., Durjava, M.K., Kolar, B., Öberg, T., Todeschini, R., 2012. Assessing bioaccumulation of polybrominated diphenyl ethers for aquatic species by QSAR modeling. Chemosphere 89, 433-444.

Marklund, A., Andersson, B., Haglund, P., 2005a. Organophosphorus flame retardants and plasticizers in air from various indoor environments. J. Environ. Monit. 7, 814-819.

Marklund, A., Andersson, B., Haglund, P., 2005b. Organophosphorus flame retardants and plasticizers in Swedish sewage treatment plants. Environ. Sci. Technol. 39, 7423-9429.

Meeker, J.D., Cooper, E.M., Stapleton, H.M., Hauser, R., 2013a. Exploratory analysis of urinary metabolites of phosphorus-containing flame retardants in relation to markers of male reproductive health. Endocr. Disruptors 1 (1).

Meeker, J.D., Cooper, E.M., Stapleton, H.M., Hauser, R., 2013b. Urinary metabolites of organophosphate flame retardants: temporal variability and correlations with house dust concentrations. Environ. Health Perspect. 121, 580-585.

Meeker, J.D., Stapleton, H.M., 2010. House dust concentrations of organophosphate flame retardants in relation to hormone levels and semen quality parameters Environ. Health Perspect. 118, 318-323.

Meyer, J., Bester, K., 2004. Organophosphate flame retardants and plasticisers in wastewater treatment plants. J. Environ. Monit. 6, 599-605.

Minegishi, K., Kurebayashi, H., Nambaru, S., Morimoto, K., Takahashi, T., Yamaha, T., 1988. Comparative studies on absorption, distribution, and excretion of flame retardants halogenated alkyl phosphate in rats. Eisei Kagaku 34, 102-114.

Moller, K., Crescenzi, C., Nilsson, U., 2004. Determination of a flame retardant hydrolysis product in human urine by SPE and LC-MS. Comparison of molecularly imprinted solid-phase extraction with a mixed-mode anion exchanger. Anal. Bioanal. Chem. 378, 197-204.

Mošat', A., Lueshen, E., Heitzig M., Hall, C., Linninger, A.A., Sin, G., Gani, R., 2013. First principles pharmacokinetic modeling: a quantitative study on Cyclosporin. Comput. Chem. Eng. 54, 97-110.

Muir, D.C.G., Grift, N.P., Blouw, A.P., Lockhart, W.L., 1980. Environmental dynamics of phosphate esters. I. Uptake and bioaccumulation of triphenyl phosphate by rainbow trout. Chemosphere 9, 525-532.

Ni, Y., Kumagai, K., Yanagisawa, Y., 2007. Measuring emissions of organophosphate flame retardants using a passive flux sampler. Atmos. Environ. 41, 3235-3240.

Nishimaki-Mogami, T., Minegishi, K.-I., Tanaka, A., Sato, M., 1988. Isolation and identification of metabolites of 2-ethylhexyl diphenyl phosphate in rats. Arch. Toxicol. 61, 259-264.

Nomeir, A.A., Kato, S., Matthews, H.B., 1981. The metabolism and disposition of Tris(1,3-dichloro-2-propyl) phosphate (Fyrol FR-2) in the rat. Toxicol. Appl. Pharmacol. 57, 401-413.

OEHHA, 2011. Evidence on the Carcinogenicity of Tris(1,3-dichloro-2-propyl)phosphate, Reproductive and Cancer Hazard Assessment Branch Office of Environmental Health Hazard Assessment. California Environmental Protection Agency, US.

Petropoulou, S.-S.E., Petreas, M., Park, J.-S., 2016. Analytical methodology using ionpair liquid chromatography-tandem mass spectrometry for the determination of four di-ester metabolites of organophosphate flame retardants in California human urine. J. Chromatogr. A 1434, 70-80.

Porter, E., Crump, D., Egloff, C., Chiu, S., Kennedy, S.W., 2014. Use of an avian hepatocyte assay and the avian toxchip polymerse chain reaction array for testing prioritization of 16 organic flame retardants. Environ. Toxicol. Chem. 33 $573-582$.

Reemtsma, T., Lingott, J., Roegler, S., 2011. Determination of 14 monoalkyl phosphates, dialkyl phosphates and dialkyl thiophosphates by LC-MS/MS in human urinary samples. Sci. total Environ. 409, 1990-1993.

Reemtsma, T., Quintana, J.B., Rodil, R., García-López, M., Rodríguez, I., 2008. Organophosphorus flame retardants and plasticizers in water and air I. Occurrence and fate. TrAC Trends Anal. Chem. 27, 727-737.

Saeger, V.W., Hicks, O., Kaley, R.G., Michael, P.R., Mieure, J.P., Tucker, E.S., 1979 Environmental fate of selected phosphate esters. Environ. Sci. Technol. 13, $840-844$.
Sasaki, K., Suzuki, T., Takeda, M., Uchiyama, M., 1984. Metabolism of phosphoric acid triesters by rat liver homogenate. Bull. Environ. Contam. Toxicol. 33, 281-288.

Sasaki, K., Takeda, M., Uchiyama, M., 1981. Toxicity, absorption and elimination of phosphoric acid triesters by killifish and goldfish. Bull. Environ. Contam. Toxicol. 27, 775-782.

Schindler, B.K., Förster, K., Angerer, J., 2009a. Determination of human urinary organophosphate flame retardant metabolites by solid-phase extraction and gas chromatography-tandem mass spectrometry. J. Chromatogr. B 877, 375-381.

Schindler, B.K., Förster, K., Angerer, J., 2009b. Quantification of two urinary metabolites of organophosphorus flame retardants by solid-phase extraction and gas chromatography-tandem mass spectrometry. Anal. Bioanal. Chem. 395, 1167-1171.

Schreder, E.D., La Guardia, M.J., 2014. Flame retardant transfers from U.S. households (dust and laundry wastewater) to the aquatic environment. Environ. Sci. Technol. 48, 11575-11583.

St John, L.E., Eldefrawi, M.E., Lisk, D.J., 1976. Studies of possible absorption of a flame retardant from treated fabrics worn by rats and humans. Bull. Environ. Contam. Toxicol. 15, 192-197.

Staaf, T., Ostman, C., 2005. Organophosphate triesters in indoor environments. J. Environ. Monit. 7, 883-887.

Stackelberg, P.E., Gibs, J., Furlong, E.T., Meyer, M.T., Zaugg, S.D., Lippincott, R.L., 2007. Efficiency of conventional drinking-water-treatment processes in removal of pharmaceuticals and other organic compounds. Sci. Total Environ. 377, 255-272.

Su, G., Crump, D., Letcher, R.J., Kennedy, S.W., 2014. Rapid in vitro metabolism of the flame retardant triphenyl phosphate and effects on cytotoxicity and mRNA expression in chicken embryonic hepatocytes. Environ. Sci. Technol. 48, 13511-13519.

Su, G., Letcher, R.J., Crump, D., Gooden, D.M., Stapleton, H.M., 2015. In vitro metabolism of the flame retardant triphenyl phosphate in chicken embryonic hepatocytes and the importance of the hydroxylation pathway. Environ. Sci. Technol. Lett. 2, 100-104.

Sundkvist, A.M., Olofsson, U., Haglund, P., 2010. Organophosphorus flame retardants and plasticizers in marine and fresh water biota and in human milk. J. Environ. Monit. 12, 943-951.

Suzuki, T., Sasaki, K., Takeda, M., Uchiyama, M., 1984. Metabolism of tributyl phosphate in male rats. J. Agric. Food Chem. 32, 603-610.

Tajima, S., Araki, A., Kawai, T., Tsuboi, T., Ait Bamai, Y., Yoshioka, E., Kanazawa, A., Cong, S., Kishi, R., 2014. Detection and intake assessment of organophosphate flame retardants in house dust in Japanese dwellings. Sci. Total Environ. 478, 190-199.

Takimoto, K., Hirakawa, T., Ito, K., Mukai, T., Okada, M., 1999. Source and transport of tricresyl phosphate (TCP) isomers in Kurose river basin. Atmos. Environ. 33, 3191-3200.

Van Ael, E., Covaci, A., Das, K., Lepoint, G., Blust, R., Bervoets, L., 2013. Factors influencing the bioaccumulation of persistent organic pollutants in food webs of the scheldt estuary. Environ. Sci. Technol, 47, 11221-11231.

Van de Waterbeemd, H., Testa, B., 2015. The Why and How of Absorption, Distribution, Metabolism, Excretion, and Toxicity Research. In: Reference Module in Chemistry, Molecular Sciences and Chemical Engineering. Elsevier, pp. 1-5.

Van den Eede, N., Dirtu, A.C., Neels, H., Covaci, A., 2011. Analytical developments and preliminary assessment of human exposure to organophosphate flame retardants from indoor dust. Environ. Int. 37, 454-461.

Van den Eede, N., Erratico, C., Exarchou, V., Maho, W., Neels, H., Covaci, A., 2015a. In vitro biotransformation of tris(2-butoxyethyl) phosphate (TBOEP) in human liver and serum. Toxicol. Appl. Pharmacol. 284, 246-253.

Van den Eede, N., Heffernan, A.L., Aylward, L.L., Hobson, P., Neels, H., Mueller, J.F., Covaci, A., 2015b. Age as a determinant of phosphate flame retardant exposure of the Australian population and identification of novel urinary PFR metabolites. Environ. Int. 74, 1-8.

Van den Eede, N., Maho, W., Erratico, C., Neels, H., Covaci, A., 2013a. First insights in the metabolism of phosphate flame retardants and plasticizers using human liver fractions. Toxicol. Lett. 223, 9-15.

Van den Eede, N., Neels, H., Jorens, P.G., Covaci, A., 2013b. Analysis of organophosphate flame retardant diester metabolites in human urine by liquid chromatography electrospray ionisation tandem mass spectrometry. J. Chromatogr. A 1303, 48-53.

Van der Veen, I., de Boer, J., 2012. Phosphorus flame retardants: properties, production, environmental occurrence, toxicity and analysis. Chemosphere 88, 1119-1153.

Waaijers, S.L., Kong, D., Hendriks, H.S., de Wit, C.A., Cousins, I.T., Westerink, R.H. Leonards, P.E., Kraak, M.H., Admiraal, W., de Voogt, P., Parsons, J.R., 2013. Persistence, bioaccumulation, and toxicity of halogen-free flame retardants. Rev. Environ. Contam. Toxicol. 222, 1-71.

Wang, Q., Lam, J.C.-W., Man, Y.-C., Lai, N.L.-S., Kwok, K.Y., Guo, Y.y., Lam, P.K.-S. Zhou, B., 2015a. Bioconcentration, metabolism and neurotoxicity of the organophorous flame retardant 1,3-dichloro 2-propyl phosphate (TDCPP) to zebrafish. Aquat. Toxicol. 158, 108-115.

Wang, R., Tang, J., Xie, Z., Mi, W., Chen, Y., Wolschke, H., Tian, C., Pan, X., Luo, Y., Ebinghaus, R., 2015b. Occurrence and spatial distribution of organophosphate ester flame retardants and plasticizers in 40 rivers draining into the Bohai Sea, north China. Environ. Pollut. 198, 172-178.

Wang, X.W., Liu, J.F., Yin, Y.G., 2010. The pollution status and research progress on organophosphate esters flame retardants. Prog. Chem. 22, 1983-1992 (in 
Chinese).

Washington Toxics Coalition, 2011. SB 6120 A Top Priority for Both the Environment \& Health Communities. UPDATE: Crunch Time For the Toxic-Free Kids Act. [Cited 16 May 2015], Available from: http://watoxics.org/campaigns/updatetoxic-free-kids-act-needs-to-be-stronger.

Wei, G.L., Li, D.Q., Zhuo, M.N., Liao, Y.S., Xie, Z.Y., Guo, T.L., Li, J.J., Zhang, S.Y., Liang, Z.Q., 2015. Organophosphorus flame retardants and plasticizers: sources, occurrence, toxicity and human exposure. Environ. Pollut. 196, 29-46.

WHO, 1990. Tricresyl Phosphate. Environmental Health Criteria 110. World Health Organization, Geneva, Switzerland.

WHO, 1991. Tributyl Phosphate. Environmental Health Criteria 112. World Health Organization, Geneva, Switzerland.
WHO, 1997. Flame Retardants: a General Introduction. Environmental Health Criteria 192. World Health Organization, Geneva, Switzerland.

WHO, 1998. Flame Retardants: Tris(Chloropropyl) Phosphate and Tris(2chloropropyl) Phosphate. Environmental Health Criteria 209, World Health Organization, Geneva, Switzerland.

WHO, 2000. Flame Retardants: Tris(2-butoxyethyl) Phosphate, Tris(2-ethylhexyl) Phosphate and Tetrakis(hydroxymethyl) Phosphonium Salts. Environmental Health Criteria 218. World Health Organization, Geneva, Switzerland.

Yang, F. Ding, J., Huang, W. Xie, W. Liu, W., 2014. Particle size-specific distribution and preliminary exposure assessments of organophosphate flame retardants in office air particulate matter. Environ. Sci. Technol. 48, 63-70. 